\title{
An Elevated HbA1c Level Is Associated With Short-Term Adverse Outcomes in Patients With Gastrointestinal Cancer and Type 2 Diabetes Mellitus
}

\author{
Yingchun Huang ${ }^{\mathrm{a}, \mathrm{e}}$, Huazhen Zheng ${ }^{\mathrm{b}, \mathrm{e}}$, Peicong Chen ${ }^{\mathrm{c}}$ e, Jin Yang ${ }^{\mathrm{c}}$, Shaomin Lin ${ }^{\mathrm{c}}$, Tingting Liu ${ }^{\mathrm{c}}$, \\ Shanwei Chen ${ }^{\mathrm{c}}$, Siqiang Lu ${ }^{\mathrm{c}}$, Junlian Chen ${ }^{\mathrm{c}}$, Wenpu Chen ${ }^{\mathrm{c},}$, , f, Nanhai Peng, ${ }^{\mathrm{a}}$,
}

\begin{abstract}
Background: Although an elevated hemoglobin Alc (HbAc1) level is an independent predictor of worse survival in patients with both digestive cancer and diabetes mellitus, its relationship to short-term prognosis in these patients has not been addressed. This study assessed this relationship in gastrointestinal cancer (GIC) patients with type 2 diabetes mellitus (T2DM).
\end{abstract}

Methods: A retrospective review of patients with GIC with or without T2DM from 2004 to 2014 was performed. Patients with T2DM were grouped according to $\mathrm{HbA} 1 \mathrm{c}$ level, either normal (mean $<7.0 \%$ ) or elevated (mean $\geq 7.0 \%$ ). Age- and sex-matched GIC patients without T2DM served as controls.

Results: One hundred and eighteen patients aged 33 - 81 years with T2DM met the study eligibility criteria; 51 were in the normal $\mathrm{HbA} 1 \mathrm{c}$ group, and 67 were in the elevated $\mathrm{HbAlc}$ group. The 91 patients in the non-T2DM group were randomly selected and matched to the T2DM group in terms of admittance date, age, and sex. There was a trend toward a higher 180-day mortality rate in the T2DM group compared with the non-T2DM group $(15.3 \%$ vs. $7.7 \%, \mathrm{P}=0.095)$ and in the elevated $\mathrm{HbA} 1 \mathrm{c}$ group compared with the normal $\mathrm{HbA} 1 \mathrm{c}$ group $(19.4 \%$ vs. $9.8 \%, \mathrm{P}=0.151)$; however, the differences were not significant. The duration of the hospital stay was longer in patients with T2DM than in those without T2DM (13.2 vs. 8.9 days, $\mathrm{P}<0.05)$ and in patients with elevated versus normal HbA1c levels (14.5 vs. 11.4

Manuscript accepted for publication June 01, 2016

aDepartment of General Surgery, Jinling Hospital, Nanjing, Jiangsu Province, China

bDepartment of Clinical Laboratory, The First People's Hospital of Foshan, Guangdong Province, China

${ }^{\circ}$ First Clinical Medical College, Guangdong Medical University, Zhanjiang, Guangdong Province, China

${ }^{\mathrm{d}}$ Department of Endocrinology, Affiliated Hospital of Guangdong Medical University, Zhanjiang, Guangdong Province, China

eThese authors contributed equally to this work.

${ }^{f}$ Corresponding Author: Wenpu Chen, Department of Endocrinology, Affiliated Hospital of Guangdong Medical University, Zhanjiang 524000, Guangdong Province, China. Email: cwenpu_gd@163.com; Nanhai Peng, Department of General Surgery, Jinling Hospital, Nanjing, Jiangsu Province, China. Email: nanhaipengnj@163.com

doi: https://doi.org/10.14740/jocmr2607w days, $\mathrm{P}<0.05)$. Diabetic GIC patients with elevated HbAlc levels had significantly more total postoperative complications than those with normal HbA1c levels $(25.4 \%$ vs. $9.8 \%, \mathrm{P}<0.05)$. In multivariate regression analyses, short-term adverse outcomes were strongly associated with elevated HbAlc levels (odds ratio (OR): 5.276; 95\% confidence level (CI): $1.73-16.095 ; \mathrm{P}<0.05)$ and no strict antidiabetic treatment (OR: 7.65; 95\% CI: 2.49 - 23.54; P < 0.001).

Conclusion: An elevated level of HbA1c significantly correlated with and was an independent predictor of short-term adverse outcomes in GIC patients with T2DM.

Keywords: HbA1c; Gastrointestinal cancer; Type 2 diabetes mellitus

\section{Introduction}

Gastrointestinal cancer (GIC), including gastric, colon, and rectal cancer, is a leading cause of cancer-associated mortality and morbidity. Worldwide in 2012, there were 1.36 million new cases of colorectal cancer, 0.95 million new cases of gastric cancer, 723,000 deaths from gastric cancer, and 694,000 deaths from colorectal cancer [1]. The high incidence and high death rate of GIC pose a serious threat to the lives and health of people all over the world in the coming decades.

GIC and diabetes mellitus (DM) are commonly diagnosed in the same individual [2], and numerous epidemiologic studies show a strong correlation between the two $[3,4]$. In a retrospective study of three patient populations by Williams et al in 1984, $\mathrm{DM}$ was more than twice as frequent in colorectal cancer patients as that in age-matched controls [5]. Another Taiwanese study, published in 2012, found that the prevalence of gastric cancer with DM was 595.0 per 100,000 people [6]. Other studies suggest that type $2 \mathrm{DM}$ (T2DM) increases the risk of developing GIC [7, 8]. In a meta-analysis by Yuhara et al [9] in 2011, DM correlated with an increased risk of colon cancer and rectal cancer, with relative risks of 1.38 and 1.20, respectively. Common risk factors, such obesity, smoking, physical inactivity, and metabolic disorders may account for the correlation of GIC and DM.

Increased cancer-associated mortality and decreased survival rates have been reported in cancer patients with T2DM compared with those without T2DM [10]. Wei et al reported that preexisting T2DM correlated with an increased incidence 
Table 1. The Characteristics of Non-T2DM and T2DM Patients With Gastrointestinal Cancer

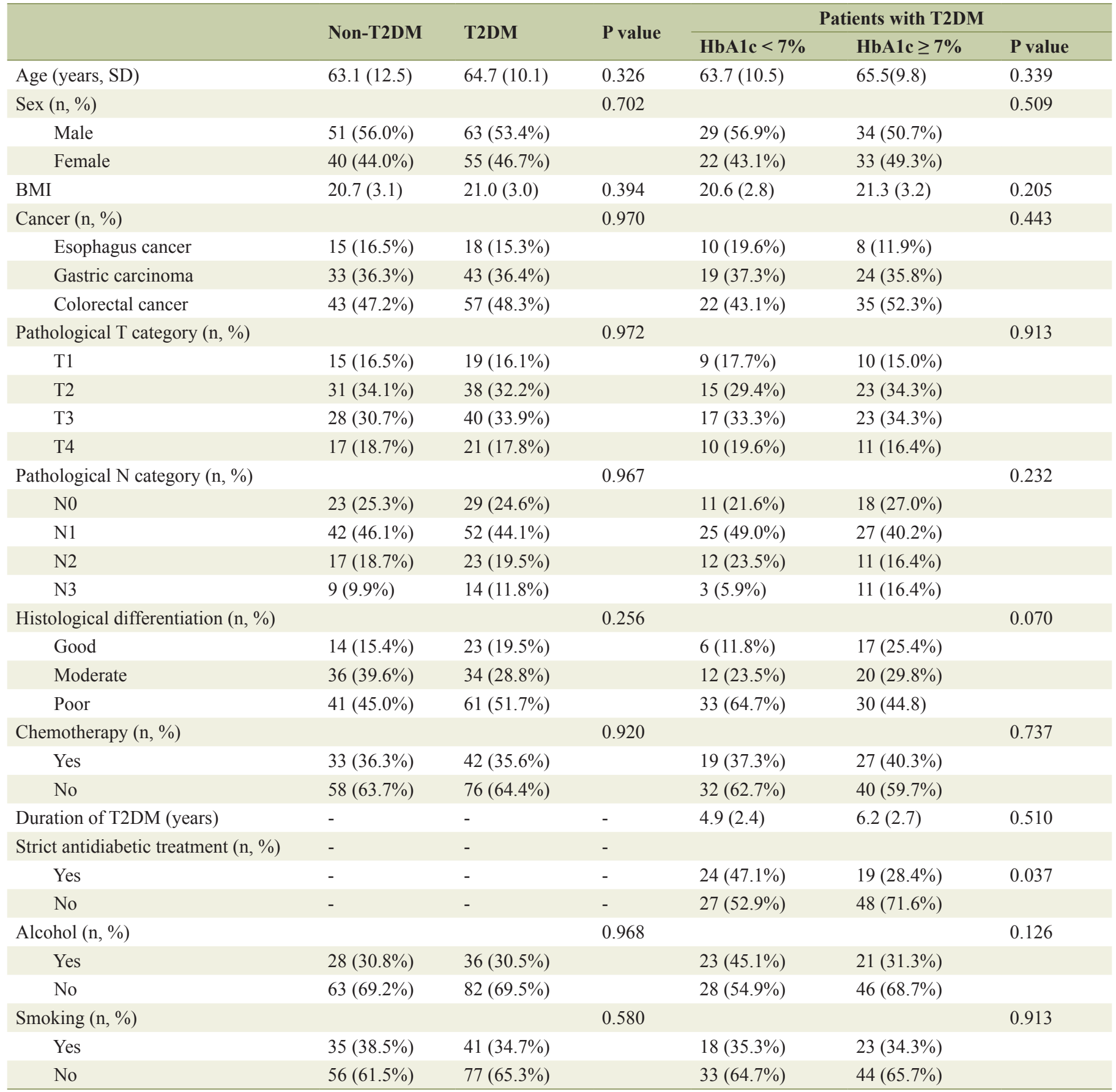

of postoperative complications and decreased survival rates in patients with gastric cancer [11]. Similarly, Chen et al found that DM was an independent predictor of increased overall mortality in patients with early colon cancer who receive curative surgery [12]. Poor prognosis has also been reported in patients with preexisting T2DM and hepatomas [13], breast cancers [14], or renal cell carcinomas [15].

The average blood glucose level over 6 - 8 weeks [16] can be approximated by measuring the level of hemoglobin A1c
(HbA1c), which is an important observational index of glucose control in DM patients in a clinical setting. Previous studies have established a relationship between HbA1c levels and cancer prognosis $[17,18]$. However, no studies have evaluated the impact of $\mathrm{HbA} 1 \mathrm{c}$ levels on short-term prognosis, including 30-day mortality, 180-day mortality, postoperative complications, and length of hospital stay in GIC patients with T2DM. The expected survival of GIC patients can be relatively short, and many surgeons are not concerned with glycemic control or 
short-term clinical outcomes in GIC patients. Herein we conducted a retrospective study to assess the association between serum $\mathrm{HbA} 1 \mathrm{c}$ levels and short-term outcomes in patients with T2DM after resection of a GIC.

\section{Materials and Methods}

\section{Patients}

The data for this retrospective case-control study were collected from Jinling Hospital and Affiliated Hospital of Guangdong Medical University (August 2004 to June 2014) in China. Study approval was obtained from the ethical committees of these hospitals. Patients were eligible for this study if they were $\geq 18$ years of age and had a primary diagnosis of GIC and 1) no T2DM, 2) T2DM with good glycemic control (normal HbAlc, $<7.0 \%$ ), or 3) T2DM with poor glycemic control (elevated $\mathrm{HbA} 1 \mathrm{c}, \geq 7.0 \%$ ). The three groups were marched for admittance date, sex and age. Diagnosis of GIC was based on the histopathologic findings in either a resection specimen or endoscopic biopsies. Patients with T2DM were identified as those with: 1) DM symptoms, including polydipsia, polyuria, and unexplained weight loss and one or more random blood glucose level $\geq 11.1 \mathrm{mmol} / \mathrm{L}(200 \mathrm{mg} / \mathrm{dL}) ; 2)$ a baseline fasting blood glucose level $\geq 7.0 \mathrm{mmol} / \mathrm{L}(126 \mathrm{mg} / \mathrm{dL})$; or 3$)$ a 2 -h glucose level $\geq 11.1 \mathrm{mmol} / \mathrm{L}(200 \mathrm{mg} / \mathrm{dL})$ in an oral glucose tolerance test [19]. Patients who required hemodialysis or had had diabetes for more than 10 years were excluded from this study.

\section{Data collection}

Medical records and follow-up data were reviewed to obtain the following clinical information: patient age, sex, body mass index (BMI), tumor type, TNM stage, alcohol consumption, smoking, medication use, overall clinical status at the onset of GIC, length of the postoperative hospital stay, postoperative complications, 30-day mortality, and 180-day mortality. We also examined the mean HbA1c levels, which served as the index of glycemic control during the entire hospital stay. On the basis of prior clinical trials $[18,20]$, patients with T2DM were divided into two groups according to their HbA1c levels: the persistently elevated $\mathrm{HbA} 1 \mathrm{c}$ group $(\mathrm{HbA} 1 \mathrm{c} \geq 7.0 \%$, poorly controlled) and the normal HbA1c group (HbA1c $<7.0 \%$, well controlled).

\section{Outcome measurements}

The short-term outcome measurements were 30-day and 180day mortality rates, postoperative complications, and length of hospital stay.

\section{Statistical analysis}

Statistical analyses were performed by using SPSS 17.0 software. Quantitative data were presented as mean (standard deviation), and categorical variables were presented as number and percentage. Differences in age, sex, short-term outcomes, and other variables between two groups were evaluated by using the Pearson Chi-square test and the independent samples $t$-test for continuous variables. A logistic regression model was established to analyze the association of the study variate with short-term adverse outcomes in patients with resectable GIC and T2DM. Univariate logistic regression analysis was used to identify possible predictors of short-term adverse outcomes. Age, sex, and all parameters with a $\mathrm{P}$ value $<0.05$ in the univariate analysis were included in multivariate analyses to identify the predictors most strongly associated with short-term adverse outcomes. For all statistical tests, a two-tailed $\mathrm{P}$ value $<0.05$ was considered statistically significant.

\section{Results}

\section{Demographic and clinical characteristics}

A total of 209 GIC patients were included in this study. The non-T2DM group consisted of 91 patients (51 men and 40 women; mean age, 63.1 years), and the T2DM group consisted of 118 patients (63 men and 55 women; mean age, 64.7 years). Fifty-one patients in the T2DM group had a normal HbA1c level, and 67 patients had an elevated HbAlc level. Demographic and clinical characteristics did not differ between the T2DM and non-T2DM groups. There was no significant difference in age, sex, or BMI among the gastrointestinal cancer patients with or without T2DM, including the patients with elevated and normal HbAlc levels (Table 1).

\section{Clinical outcomes}

\section{The 30-day and 180-day mortality rates}

The 30-day mortality rate did not differ significantly between the T2DM group and the non-T2DM control group $(2.5 \% \mathrm{vs}$. $2.2 \%, \mathrm{P}=0.872$, Table 2 ). At 180 days, $15.3 \%$ of the patients in the T2DM group had died, and $7.7 \%$ in the non-T2DM group had died; this difference was not significant $(\mathrm{P}=0.095$, Table 2). In the patients with T2DM, there was no difference in the 30-day mortality rate between those with elevated $\mathrm{HbA1c}$ levels and those with normal HbAlc levels ( $0 \%$ vs. $2.0 \%, \mathrm{P}$ $=0.250)$. There was a trend toward higher 180-day mortality rates in the elevated HbA1c group compared with the normal HbA1c group (19.4\% vs. 9.8\%), but the difference between the groups was not significant $(\mathrm{P}=0.151)$.

\section{Total postoperative complications}

Postoperative complications occurred in 10 patients $(11.0 \%)$ in the non-T2DM control group and 22 patients $(18.7 \%)$ in the 
Table 2. The Comparison of the Clinical Outcomes Between Non-T2DM and T2DM Patients With Gastrointestinal Cancer

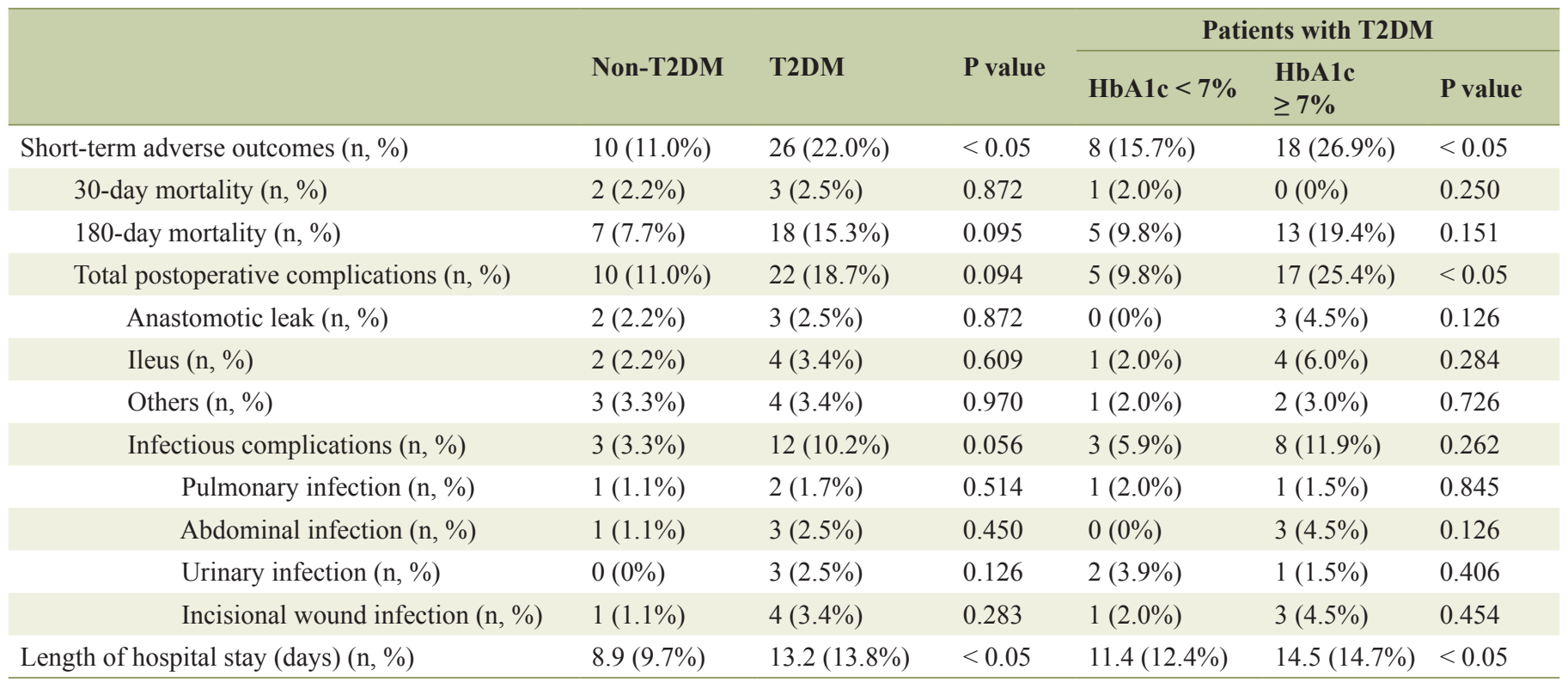

T2DM group $(\mathrm{P}=0.094)$. In the T2DM group, $9.8 \%$ of patients with normal HbA1c levels had postoperative complications compared with $25.4 \%$ of patients with elevated $\mathrm{HbA} 1 \mathrm{c}$ levels $(\mathrm{P}<0.05$, Table 2$)$. The incidence rates of postoperative infectious complications were $3.3 \%$ and $10.2 \%$ in the nonT2DM and T2DM groups, respectively $(\mathrm{P}=0.056)$, and $5.9 \%$ and $11.9 \%$ in the normal HbAlc and elevated HbAlc groups, respectively $(\mathrm{P}=0.262)$. Three patients in the elevated $\mathrm{HbA} 1 \mathrm{c}$ group developed an anastomotic leak, and four developed an ileus.

\section{Length of the hospital stay}

The duration of the hospital stay was significantly longer in the T2DM group than the non-T2DM group (13.2 vs. 8.9 days, $\mathrm{P}<0.05)$ and in T2DM patients with elevated versus normal
HbA1c levels (11.4 vs. 14.5 days, $\mathrm{P}<0.05$, Table 2 ).

\section{Short-term adverse outcomes and logistic regression anal- ysis}

The incidence rate of short-term adverse outcomes, including mortality rates and postoperative complications, was higher in the T2DM group than the non-T2DM group $(22.0 \%$ vs. $11.0 \%$, $\mathrm{P}<0.05)$. It was also higher in the elevated $\mathrm{HbA} 1 \mathrm{c}$ group than the normal HbA1c group $(26.9 \%$ vs. $15.7 \%, \mathrm{P}<0.05)$. In a univariate logistic analysis of patients with T2DM, the following variables significantly correlated with short-term adverse outcomes (Table 3): no chemotherapy (odds ratio (OR): 4.08; 95\% confidence interval $(\mathrm{CI}): 1.65-10.13$; $\mathrm{P}<0.01), \mathrm{HbA} 1 \mathrm{c}$ $\geq 7 \%$ (OR: 3.43 ; 95\% CI: $1.27-9.27$; P $<0.05$ ), and no strict antidiabetic treatment (OR: 5.87; 95\% CI: 2.04 - 18.8; $\mathrm{P}<$

Table 3. Univariate and Multivariate Logistic Analysis for Risk Factors Associated With Short-Term Adverse Outcomes in T2DM Patients With GIC

\begin{tabular}{|c|c|c|c|c|}
\hline \multirow{2}{*}{ Variable } & \multicolumn{2}{|c|}{ Univariate analysis } & \multicolumn{2}{|c|}{ Multivariate analysis } \\
\hline & Odds ratio $(95 \% \mathrm{CI})$ & P value & Odds ratio $(95 \% \mathrm{CI})$ & P value \\
\hline Age $\geq 65$ years & $2.39(0.83-6.91)$ & 0.108 & - & - \\
\hline Pathological T category $\geq \mathrm{T} 3-4$ & $1.55(0.63-3.85)$ & 0.341 & - & - \\
\hline Pathological N category $\geq N 3-4$ & $1.28(0.85-1.93)$ & 0.236 & - & - \\
\hline Alcohol & $1.475(1.48-3.530)$ & 0.383 & - & - \\
\hline Smoking & $1.14(0.47-2.782)$ & 1.139 & - & - \\
\hline No strict antidiabetic treatment & $5.87(2.04-18.8)$ & $<0.01$ & $7.65(2.49-23.54)$ & $<0.001$ \\
\hline
\end{tabular}


0.01). The variables not associated with short-term adverse outcomes were as follows: age $\geq 65$ years (OR: $2.39 ; 95 \% \mathrm{CI}$ : 0.83 - 6.91; $\mathrm{P}=0.108), \mathrm{BMI}<18 \mathrm{~kg} / \mathrm{m}^{2}$ (OR: $2.67 ; 95 \% \mathrm{CI}$ : $0.57-12.42 ; \mathrm{P}=0.211)$, pathological $\mathrm{T}$ category $\geq \mathrm{T} 3(\mathrm{OR}$ : $1.55 ; 95 \%$ CI: $0.63-3.85 ; \mathrm{P}=0.341)$, pathological $\mathrm{N}$ category $\geq \mathrm{N} 3$ (OR: 1.28 ; 95\% CI: 0.85 - 1.93; P=0.236), alcohol consumption (OR: 1.475 ; 95\% CI: $1.48-3.530 ; \mathrm{P}=0.383$ ), and smoking (OR: 1.14; 95\% CI: 0.47 - 2.782; $\mathrm{P}=1.139$ ). Multivariate logistic analysis showed that only $\mathrm{HbA} 1 \mathrm{c} \geq 7 \%$ (OR: 5.28; 95\% CI: $1.73-16.1 ; \mathrm{P}<0.05)$ and no strict antidiabetic treatment (OR: 7.65; 95\% CI: 2.49 - 23.54; P < 0.01) were significant predictors of short-term adverse outcomes in GIC patients with T2DM.

\section{Discussion}

The effect of elevated HbA1c levels on short-term clinical outcomes in patients with resectable GIC and T2DM is unknown. The present study showed that GIC patients with T2DM had a higher incidence of short-term adverse outcomes than patients without T2DM. T2DM patients with $\mathrm{HbA} 1 \mathrm{c} \geq 7 \%$ had a higher incidence of total postoperative complications and longer hospital stays than did patients with $\mathrm{HbA} 1 \mathrm{c}<7 \%$. In a logistic regression analysis, $\mathrm{HbAlc} \geq 7 \%$ and no strict antidiabetic treatment correlated with short-term adverse outcomes. These results suggest that GIC patients with preexisting diabetes are more likely to have poor outcomes than those without.

Numerous epidemiological studies have shown that patients with T2DM have a higher risk of developing malignant tumors of the digestive system, such as gastric, colorectal, liver, and pancreatic, than do patients without T2DM [7, 21-23]. Hence, whether poor glycemic control adversely affects clinical prognosis in patients with these cancers and D2TM is now receiving close attention. The level of $\mathrm{HbAlc}$ is a good indicator of plasma glucose control over a period of 6 - 8 weeks in DM patients [16] and is related to clinical outcomes. However, no studies to date have assessed the association between $\mathrm{HbA1c}$ level and short-term mortality in patients with GIC. As a novel finding, our study shows that an elevated $\mathrm{HbA} 1 \mathrm{c}$ level is a strong independent predictor of short-term adverse outcomes. The incidence rate of short-term adverse outcomes was $26.9 \%$ in the elevated HbA1c group and $15.7 \%$ in the normal HbA1c group $(\mathrm{P}<0.05)$. Although the differences were not significant, there was a trend toward a higher 180-day mortality rate in the elevated $\mathrm{HbA} 1 \mathrm{c}$ group compared with the normal HbA1c group. The lack of statistical significance may reflect in part the relatively small number of patients in our study.

Our findings on survival rate are similar to those of two previous studies, although their clinical index was long-term survival rate. Siddiqui et al showed that high $\mathrm{HbAlc}$ levels correlated with worse 5-year survival rates in patients with colorectal cancer and T2DM (OR: $0.31 ; 95 \%$ CI: $0.16-0.62$ ) [17]. Cheon et al found that elevated serum HbA1c levels potentially correlated with poor survival in diabetic patients with advanced pancreatic cancer [18]. Our results are also similar to previous evidence suggesting that preexisting diabetes is independently associated with increased mortality rates in pa- tients undergoing surgery for gastric [11] or pancreatic [24, 25] cancer. There are three potential explanations of the association between elevated HbAlc levels and short-term adverse outcomes in GIC patients with T2DM. First, elevated glycemic levels increase oxidative stress by altering the metabolism of lipids and lipoproteins [26]; both abnormal lipid metabolism and oxidative stress have been shown to stimulate tumor cell proliferation [27, 28]. Hyperglycemia-induced tumor cell invasion and migration is also possible [29]. Second, insulinlike growth factor-1 (IGF-1) receptors become active owing to long-term exposure of patients with T2DM to high circulating levels of insulin $[19,30]$. Experimental studies have demonstrated that high insulin and IGF-1 levels promote the growth of cancer cells [31, 32]. Third, hyperglycemia increases the risk of intraoperative mortality. However, mortality rates were not significantly different between the T2DM and non-T2DM groups in our study. The events listed above might also lead to poor prognosis in cancer patients with T2DM.

Our study confirms that elevated HbA1c levels increase the incidence of postoperative complications in patients with T2DM. Previous studies have shown that diabetics have a higher risk of postoperative complications after general surgery than do non-diabetics $[33,34]$. In the absence of pharmacologic treatment, elevated levels of serum HbA1c in diabetic patients were associated with an increased risk of severe complications in the first 30 days after surgery in the study by Stenberg et al in 2014 [35]. This result is in line with our results. Blood glucose levels commonly fluctuate widely in diabetics compared with non-diabetics. That hyperglycemia may be an important risk factor for postoperative infectious morbidity has become increasingly recognized [36, 37]. Furthermore, many studies have associated hyperglycemia with surgical site infections after colorectal surgery [38, 39]. Our study did not find a significant difference in the incidence of infectious complications between the normal $\mathrm{HbAlc}$ and elevated HbAlc groups; however, larger studies are required to generate more robust data.

A preoperative level of $\mathrm{HbAlc}>8 \%$ has been significantly associated with longer hospital stays [40]. Our results are consistent with this finding: we demonstrated that diabetic GIC patients with poor glycemic control ( $\mathrm{HbA} 1 \mathrm{c} \geq 7 \%$ ) had longer hospital stays than those with good glycemic control $($ HbA $1 \mathrm{c}<7 \%$ ) (22.5 vs. 19.4 days). However, whether hyperglycemia or an elevated HbA1c level lengthens hospital stays has been controversial. In an American study, postoperative hyperglycemia correlated with longer hospital stays in patients who underwent complex ventral hernia repair [41]. In a study of patients undergoing total joint arthroplasty, the incidence of prolonged hospital stays was higher in diabetic patients with a preoperative level of $\mathrm{HbA} 1 \geq 10 \%$ (uncontrolled) than in patients with diabetes [42]. However, in a recent systematic review of 19,514 patients with DM, preoperative HbA1c levels did not correlate with total hospital length of stay [43]. From another perspective, the increased likelihood of morbidity in patients with poor glycemic control predicts that their hospital stays would be significantly longer than the hospital stays of patients with good glycemic control.

In our study, 30-day mortality, 180-day mortality, and postoperative complications were defined as short-term ad- 
verse outcomes. Compared with an $\mathrm{HbA} 1 \mathrm{c}$ level $<7 \%$, our multivariate logistic analysis showed that an HbAlc level $\geq$ $7 \%$ predicted short-term adverse outcomes in diabetic GIC patients. We suggest that an elevated HbA1c level indicates a poor clinical outcome in diabetic cancer patients. Siddiqui et al suggested that poor glycemic control shortens the 5-year survival rate in diabetic patients with colorectal cancer and foretells a clinically aggressive course of the cancer [17]. We believe that an elevated HbA1c level is not only associated with poor long-term prognosis, but also with negative shortterm outcomes.

There were several limitations to our study. First, it was a retrospective case-control study, and some selection biases may have existed. Second, the number of eligible patients in our study was relatively small, which may have compromised the statistical power. Third, the adequacy and effectiveness of the antidiabetic treatments during or after hospitalization may have influenced the clinical outcomes. We were unable to analyze changes in HAb1c levels after antidiabetic treatment owing to incomplete data.

In conclusion, the present study suggests that an elevated $\mathrm{HAb} 1 \mathrm{c}$ level is associated with short-term adverse clinical outcomes in patients with both resectable GIC and T2DM. Poorer glycemic control in diabetic cancer patients correlated with longer hospital stays. Early detection of changes in HAb1c levels in combination with a strict antidiabetic treatment may improve the poor prognosis of GIC patients with T2DM. Large-scale prospective studies are needed to clarify the relationship between elevated $\mathrm{HbA} 1 \mathrm{c}$ levels and short- and long-term outcomes.

\section{Conflicts of Interest}

The authors declare no conflicts of interest.

\section{Source of Funding}

None.

\section{References}

1. Ferlay J, Soerjomataram I, Dikshit R, Eser S, Mathers C, Rebelo M, Parkin DM, et al. Cancer incidence and mortality worldwide: sources, methods and major patterns in GLOBOCAN 2012. Int J Cancer. 2015;136(5):E359-386.

2. Onitilo AA, Engel JM, Glurich I, Stankowski RV, Williams GM, Doi SA. Diabetes and cancer I: risk, survival, and implications for screening. Cancer Causes Control. 2012;23(6):967-981.

3. Giovannucci E, Harlan DM, Archer MC, Bergenstal RM, Gapstur SM, Habel LA, Pollak M, et al. Diabetes and cancer: a consensus report. CA Cancer J Clin. 2010;60(4):207-221.

4. Yang YX, Hennessy S, Lewis JD. Type 2 diabetes mellitus and the risk of colorectal cancer. Clin Gastroenterol
Hepatol. 2005;3(6):587-594.

5. Williams JC, Walsh DA, Jackson JF. Colon carcinoma and diabetes mellitus. Cancer. 1984;54(12):3070-3071.

6. Tseng $\mathrm{CH}$. Diabetes, insulin use, and gastric cancer: a population-based analysis of the Taiwanese. Journal of Clinical Gastroenterology. 2013;47(6):60-64.

7. Sekikawa A, Fukui H, Maruo T, Tsumura T, Okabe Y, Osaki Y. Diabetes mellitus increases the risk of early gastric cancer development. Eur J Cancer. 2014;50(12):20652071.

8. Larsson SC, Orsini N, Wolk A. Diabetes mellitus and risk of colorectal cancer: a meta-analysis. J Natl Cancer Inst. 2005;97(22):1679-1687.

9. Yuhara H, Steinmaus C, Cohen SE, Corley DA, Tei Y, Buffler PA. Is diabetes mellitus an independent risk factor for colon cancer and rectal cancer? Am J Gastroenterol. 2011;106(11):1911-1921; quiz 1922.

10. Liu X, Ji J, Sundquist K, Sundquist J, Hemminki K. The impact of type 2 diabetes mellitus on cancer-specific survival: a follow-up study in Sweden. Cancer. 2012;118(5):1353-1361.

11. Wei ZW, Li JL, Wu Y, Xia GK, Schwarz RE, He YL, Zhang CH. Impact of pre-existing type-2 diabetes on patient outcomes after radical resection for gastric cancer: a retrospective cohort study. Dig Dis Sci. 2014;59(5):10171024.

12. Chen KH, Shao YY, Lin ZZ, Yeh YC, Shau WY, Kuo $\mathrm{RN}$, Chen HM, et al. Type 2 diabetes mellitus is associated with increased mortality in Chinese patients receiving curative surgery for colon cancer. Oncologist. 2014;19(9):951-958.

13. Wang YG, Wang P, Wang B, Fu ZJ, Zhao WJ, Yan SL. Diabetes mellitus and poorer prognosis in hepatocellular carcinoma: a systematic review and meta-analysis. PLoS One. 2014;9(5):e95485.

14. Erickson K, Patterson RE, Flatt SW, Natarajan L, Parker BA, Heath DD, Laughlin GA, et al. Clinically defined type 2 diabetes mellitus and prognosis in early-stage breast cancer. J Clin Oncol. 2011;29(1):54-60.

15. Vavallo A, Simone S, Lucarelli G, Rutigliano M, Galleggiante V, Grandaliano G, et al. Pre-existing Type 2 Diabetes Mellitus Is an Independent Risk Factor for Mortality and Progression in Patients With Renal Cell Carcinoma. Medicine (Baltimore). 2014;93:183.

16. Bunn HF, Gabbay KH, Gallop PM. The glycosylation of hemoglobin: relevance to diabetes mellitus. Science. 1978;200(4337):21-27.

17. Siddiqui AA, Spechler SJ, Huerta S, Dredar S, Little $\mathrm{BB}$, Cryer B. Elevated HbA1c is an independent predictor of aggressive clinical behavior in patients with colorectal cancer: a case-control study. Dig Dis Sci. 2008;53(9):2486-2494.

18. Cheon YK, Koo JK, Lee YS, Lee TY, Shim CS. Elevated hemoglobin A1c levels are associated with worse survival in advanced pancreatic cancer patients with diabetes. Gut Liver. 2014;8(2):205-214.

19. Siddiqui AA, Maddur H, Naik S, Cryer B. The association of elevated $\mathrm{HbA} 1 \mathrm{c}$ on the behavior of adenomatous polyps in patients with type-II diabetes mellitus. Dig Dis 
Sci. 2008;53(4):1042-1047.

20. Liao WI, Sheu WH, Chang WC, Hsu CW, Chen YL, Tsai SH. An elevated gap between admission and A1Cderived average glucose levels is associated with adverse outcomes in diabetic patients with pyogenic liver abscess. PLoS One. 2013;8(5):e64476.

21. Wu L, Yu C, Jiang H, Tang J, Huang HL, Gao J, Zhang $\mathrm{X}$. Diabetes mellitus and the occurrence of colorectal cancer: an updated meta-analysis of cohort studies. Diabetes Technol Ther. 2013;15(5):419-427.

22. El-Serag HB, Hampel H, Javadi F. The association between diabetes and hepatocellular carcinoma: a systematic review of epidemiologic evidence. Clin Gastroenterol Hepatol. 2006;4(3):369-380.

23. Brodovicz KG, Kou TD, Alexander CM, O'Neill EA, Engel SS, Girman CJ, Goldstein BJ. Impact of diabetes duration and chronic pancreatitis on the association between type 2 diabetes and pancreatic cancer risk. Diabetes Obes Metab. 2012;14(12):1123-1128.

24. Cannon RM, LeGrand R, Chagpar RB, Ahmad SA, McClaine R, Kim HJ, Rupp C, et al. Multi-institutional analysis of pancreatic adenocarcinoma demonstrating the effect of diabetes status on survival after resection. HPB (Oxford). 2012;14(4):228-235.

25. Chu CK, Mazo AE, Goodman M, Egnatashvili V, Sarmiento JM, Staley CA, Galloway JR, et al. Preoperative diabetes mellitus and long-term survival after resection of pancreatic adenocarcinoma. Ann Surg Oncol. 2010;17(2):502-513.

26. Delmas-Beauvieux MC, Peuchant E, Thomas MJ, Dubourg L, Pinto AP, Clerc M, Gin H. The place of electron spin resonance methods in the detection of oxidative stress in type 2 diabetes with poor glycemic control. Clin Biochem. 1998;31(4):221-228.

27. Stamp D, Zhang XM, Medline A, Bruce WR, Archer MC. Sucrose enhancement of the early steps of colon carcinogenesis in mice. Carcinogenesis. 1993;14(4):777-779.

28. Richardson LC, Pollack LA. Therapy insight: Influence of type 2 diabetes on the development, treatment and outcomes of cancer. Nat Clin Pract Oncol. 2005;2(1):48-53.

29. Xu CX, Zhu HH, Zhu YM. Diabetes and cancer: Associations, mechanisms, and implications for medical practice. World J Diabetes. 2014;5(3):372-380.

30. Giovannucci E. Insulin, insulin-like growth factors and colon cancer: a review of the evidence. J Nutr. 2001;131(11 Suppl):3109S-3120S.

31. Tran TT, Medline A, Bruce WR. Insulin promotion of colon tumors in rats. Cancer Epidemiol Biomarkers Prev. 1996;5(12):1013-1015.
32. Djiogue S, Nwabo Kamdje AH, Vecchio L, Kipanyula MJ, Farahna M, Aldebasi Y, Seke Etet PF. Insulin resistance and cancer: the role of insulin and IGFs. Endocr Relat Cancer. 2013;20(1):R1-R17.

33. Yanaga K, Matsumata T, Hayashi H, Shimada M, Urata K, Suehiro T, Sugimachi K. Effect of diabetes mellitus on hepatic resection. Arch Surg. 1993;128(4):445-448.

34. Chen SY, Zhou YB, Wang H, Li SK, Mao WZ, Wang HB. [Risk factors of intra-abdominal infection following gastrectomy in gastric cancer patients]. Zhonghua Wei Chang Wai Ke Za Zhi. 2009;12(2):137-140.

35. Stenberg E, Szabo E, Naslund I. Is glycosylated hemoglobin A1 c associated with increased risk for severe early postoperative complications in nondiabetics after laparoscopic gastric bypass? Surg Obes Relat Dis. 2014;10(5):801-805.

36. Dronge AS, Perkal MF, Kancir S, Concato J, Aslan M, Rosenthal RA. Long-term glycemic control and postoperative infectious complications. Arch Surg. 2006;141(4):375-380; discussion 380.

37. Ata A, Lee J, Bestle SL, Desemone J, Stain SC. Postoperative hyperglycemia and surgical site infection in general surgery patients. Arch Surg. 2010;145(9):858-864.

38. Sehgal R, Berg A, Figueroa R, Poritz LS, McKenna KJ, Stewart DB, Koltun WA. Risk factors for surgical site infections after colorectal resection in diabetic patients. J Am Coll Surg. 2011;212(1):29-34.

39. Ata A, Valerian BT, Lee EC, Bestle SL, Elmendorf SL, Stain SC. The effect of diabetes mellitus on surgical site infections after colorectal and noncolorectal general surgical operations. Am Surg. 2010;76(7):697-702.

40. Underwood P, Askari R, Hurwitz S, Chamarthi B, Garg R. Preoperative $\mathrm{A} 1 \mathrm{C}$ and clinical outcomes in patients with diabetes undergoing major noncardiac surgical procedures. Diabetes Care. 2014;37(3):611-616.

41. Won EJ, Lehman EB, Geletzke AK, Tangel MR, Matsushima K, Brunke-Reese D, Pichardo-Lowden AR, et al. Association of postoperative hyperglycemia with outcomes among patients with complex ventral hernia repair. JAMA Surg. 2015;150(5):433-440.

42. Kallio PJ, Nolan J, Olsen AC, Breakwell S, Topp R, Pagel PS. Anesthesia Preoperative Clinic Referral for Elevated Hba1c Reduces Complication Rate in Diabetic Patients Undergoing Total Joint Arthroplasty. Anesth Pain Med. 2015;5(3):e24376.

43. Rollins KE, Varadhan KK, Dhatariya K, Lobo DN. Systematic review of the impact of $\mathrm{HbA} 1 \mathrm{c}$ on outcomes following surgery in patients with diabetes mellitus. Clin Nutr. 2016;35(2):308-316. 